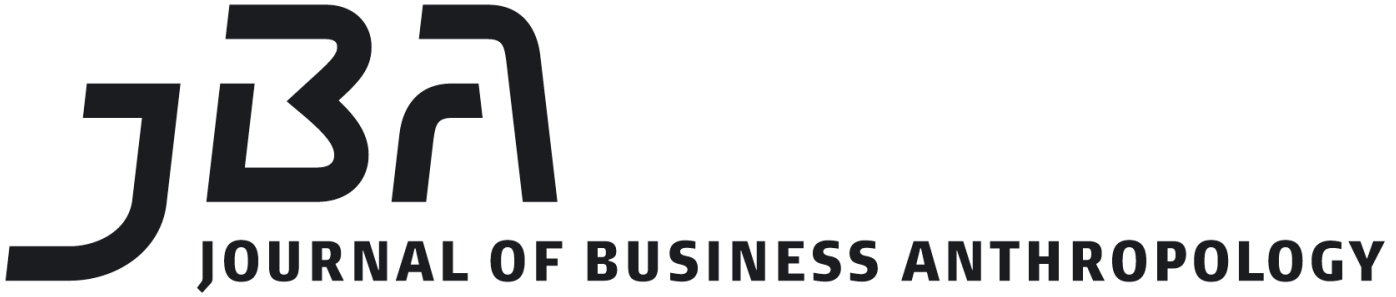

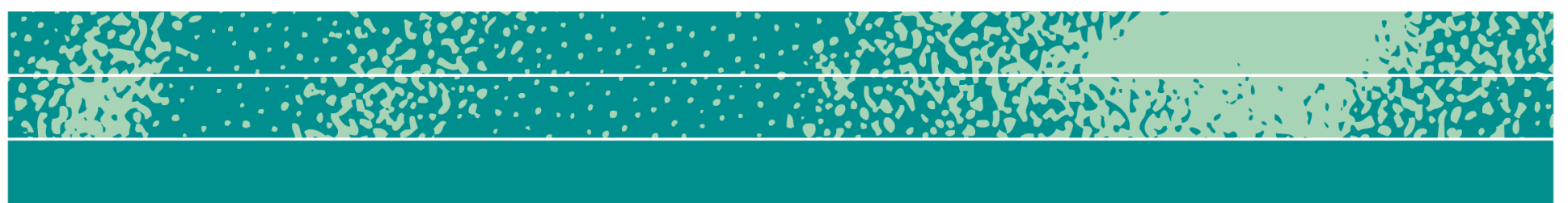

\section{The Gift and Pay-What-You-Want Pricing}

\author{
Henrik Egbert
}

\begin{abstract}
This paper addresses the participative pricing mechanism of Pay-WhatYou-Want pricing as related to Marcel Mauss's concept of the Gift. Reciprocity is a behavioural pattern imminent to the Gift as well as to Pay-What-You-Want pricing. The paper refers to results from behavioural economics in order to identify factors that positively influence reciprocity. It is argued that the aspects elaborated on in the Gift are also relevant to the PWYW pricing mechanism when it comes to implementations of the latter as one of the corporate pricing strategies.
\end{abstract}

Page 1 of 13

JBA 6(2): 218-230 Autumn 2017

(C) The Author(s) 2017 ISSN 2245-4217

www.cbs.dk/jba

\section{Keywords}

Gift, Marcel Mauss, Pay-What-You-Want, PWYW, Pricing, Reciprocity

\section{Introduction}

Economic theories allow predicting decisions. In some cases these theories work well, while they fail in others. The neoclassical theory can serve as an example. Despite its radical assumptions, this theory can be used to predict the behaviour of a considerable number of individuals (not all, though) well (cf. Carrier 2014 and the comment by Egbert 2015). In other situations the same theory can hardly be applied in order to predict or explain choices. A similar statement can be made for other 
economic theories. The problem can be elucidated by the example of participative pricing.

Recently some companies have started selling products via PayWhat-You-Want (PWYW) pricing. This pricing scheme is an alternative to fixed or posted prices, auctions or price bargaining. PWYW pricing allows the buyer to determine the price of the purchased product. The seller has to accept the price that the buyer determines. Neoclassical theory assumes rational and egoistic individuals and predicts that in a one-shot anonymous interaction a utility maximizing buyer pays no more than the minimum price. However, in applied PWYW situations this is not always the case. Empirical evidence shows that many buyers often pay more than the minimum price. These findings are in line with theories of other regarding preferences. Furthermore, even if buyers pay more than a minimum price, this pricing mechanism is bound to fail if payments are too low to cover the production costs. In this case the application of PWYW pricing can have negative effects on a corporate profit even if people do not behave selfishly.

PWYW pricing provides buyers with the opportunity to pay sellers the price of their choice. This payment can be seen as a reciprocation for a good that has been sold to them. The problem for a private company can be described as follows: While it is known that many customers have other regarding preferences, reciprocity being among them, how can these preferences be made fruitful for a profit-oriented company if PWYW pricing is applied (see also Reisman 2016)? I argue in this paper that the concept of the Gift, as developed by Marcel Mauss about 100 years ago, provides guidance in order to make PWYW pricing a success for a company. The Gift has not been addressed in the rapidly growing number of studies on PWYW pricing recently, and this short paper closes this gap.

The next section provides a brief introduction to PWYW pricing. After that the concept of the Gift is addressed and its peculiarities with respect to the discussions on reciprocity and gift-giving in economics are shown. Hence, the trust game is used as an illustration. In the final section aspects that can be derived from the Gift in order to utilize PWYW pricing in a business context are pointed out.

\section{Pay-What-You-Want Pricing}

PWYW is participative pricing in which a buyer can choose the price of a product. In particular cases the seller sets a positive minimum price but, mostly, buyers are free to pay any price including zero. The seminal paper of Kim, Natter and Spann (2009) initiated research on PWYW pricing. Related papers mushroomed in the last few years (for surveys see Gerpott 2017; Greiff and Egbert 2016a; Krzyżanowska and Tkaczyk 2016). Empirical research on the topic includes laboratory experiments, 
field experiments, survey experiments and case studies.

Factors that have been identified to influence the prices paid are: preferences (e.g., social preferences like fairness, inequity aversion, or reciprocity), information (e.g., about sellers, buyers, and payments, about reference prices and costs), social interaction (e.g., communication), individual characteristics (income, age, gender), emotions (feeling of guilt), contextual factors (social distance, market structure, customer satisfaction).

The numerous studies address a large variety of products and often services. Results from recent research allow the conclusion that in business practice PWYW pricing is used almost exclusively for low-cost goods and experience goods. Furthermore, nearly all empirical studies report the application for relatively short-time periods (as an exception see Riener and Traxler 2012). Moreover, most of the business studies do not report failure of the mechanisms (as exceptions see León, Noguera and Tena-Sánchez 2012; Park, Nam and Lee 2016). One can expect a bias in the documented case studies because a company is unlikely to report about the pricing mechanism if it does not increase its profits. To sum up, neither from behavioural theories, nor from recent empirical research is it possible to predict exactly whether or not the implementation of a PWYW pricing mechanism increases the profit of a specific company. So far only selected variables and structures that influence revenue and profit have been identified.

This statement is also true if reciprocity as a driver of decision is being considered. For three decades now, reciprocity turned into a central topic in economics (Fehr, Kirchsteiger and Riedl 1993; Berg, Dickhaut and McCabe 1995; Fehr and Gächter 1998; 2000). The rise of behavioural economics provides evidence that many economists have accepted the importance of other regarding preferences-reciprocity being one of them (Mercier Ythier 2006). However, reciprocity and gift-giving as applied in behavioural economics are different from the concept of the Gift introduced by Mauss. Next, I sketch out the main difference.

\section{Reciprocity, the Trust Game and the Gift}

In this section I firstly reflect on the concept of positive reciprocity as it is used in behavioural economics. Secondly, a brief summary of the core ideas of the Gift follows. Thirdly, the most important differences between both concepts are pointed out with the trust game, as a case in point.

The observation that people do not behave selfishly but reciprocate in many situations has been integrated into economic theories. These are summarized as theories of other regarding preferences (Fehr and Schmidt 2006). Fehr and Gächter (1998) argue that many people are not selfish but behave reciprocally. They describe 
positive reciprocity as "[...] the impulse or desire to be kind to those who have been kind to us." (Fehr and Gächter 1998: 845; see additionally Albert et al. 2007; Falk and Fischbacher 2006; Fehr and Fischbacher 2003). Remarkable are the results of Fehr, Kirchsteiger and Riedl (1993). In an experiment they find that a considerable number of buyers pay a high price in order to give an incentive for sellers to provide a higher quality of a good. On average, half of the sellers in the experiment reacted with a positive reciprocity, i.e. with a higher product quality (Fehr, Kirchsteiger and Riedl 1993: 438-9; also Fehr, Kirchsteiger and Riedl 1998). Fehr and Gächter (2000: 160) argue that one of the consequences of reciprocity is to enforce social norms in collective settings. Whether selfish or non-selfish preferences dominate within a group of deciders is influenced by the institutional framework.

Besides the abundance of experimental evidence on the ubiquitous existence of positive reciprocity in laboratory settings (e.g., in the trust game, and the gift-exchange game), field experiments (Falk 2008) also confirm this behaviour and evolutionary simulations show distributions of different types of preferences within a population over time (e.g., Bowles and Gintis 2004; Bowles, Choi and Hopfensitz 2003). Fehr and Schmidt (2006: 618) describe the state of research in economic theory by outlining that it is not a question anymore whether individuals have (apart from material selfishness) other-regarding preferences. The question is rather about the conditions and related social effects of such preferences. Such conditions and social effects are addressed by Marcel Mauss.

Mauss's (1923/1924) concept of the Gift is rarely referred to in economics. According to Mauss, the individual decision is conditioned by both individual freedom and social obligations (Hart 2007: 481). In Mauss's words (1990: 70) an individual "[...] must act by taking account of his own interests, and those of the society and its subgroups." That is why a person's behaviour has an individual and a social orientation alike. The concept of the Gift tackles both.

Mauss's system of total services can be understood as an institutional setting which includes collective entities, rules and obligations of exchange (Douglas 1990: 5). Exchange in this system is compulsory and ubiquitous, and can embrace nearly everything. Douglas provides examples of exchange, such as banquets, rituals, military services, and cultural activities. As collective entities which engage in exchange, Mauss addresses families, clans and tribes. Indeed, exchange has a strong competitive element if one group or an individual tries to outperform counterparts in a situation of repeated reciprocal giving.

It is important to note that Mauss's writings allow a universal application of the Gift, i.e. the concept can be applied to modern market exchange as much as to 'archaic exchange' (see Hart 2007 for the history 
of the interpretation of Mauss) and that the concept is related to an evolutionary process (Hann 2006: 208). Assuming that the Gift is a universal concept (Liebersohn 2011: 139-164) and captures many types of exchange in modern states and other organizations, I argue that it is applicable to a large number of social interactions today. Thus, the analysis of collective exchange systems may include team work, science, hierarchies, or pricing systems and also modern organizations, such as sport clubs, bureaucracies, schools, or private enterprises.

The reasons why I build my argument on Mauss, are, firstly, that he is the first among the prominent ones who develops a generalized view on gifts and reciprocity applicable for every society, and, secondly, that his theoretical work became the cornerstone for theories on reciprocity in anthropology, and inspired the work of Polanyi, Lévi-Strauss, and Sahlins. This position does not ignore that it is Malinowski (1922), one of Mauss's central sources, who pointedly addresses gifts and counter-gifts. In his compact book, published shortly after Mauss (1923/24), Malinowski (1926) most beautifully illustrates the complexity of exchange and obligations. Neither do I ignore the critique on Mauss, as articulated, for instance, by Parry (1986), nor am I unaware that other anthropological concepts of exchange go beyond reciprocity, such as Weiner's (1992) 'keeping-while-giving'. Nonetheless, for the purpose of this paper the reference to Mauss will suffice.

When Mauss (1990, 39-43) illustrates the concept of the Gift, he refers to potlatch cultures from the Pacific and North America and to historical examples from Europe and Asia. The Gift in its original forms is characterized by three immanent obligations. The first one is the obligation to give, which is ubiquitous and central for groups or for individuals. Both have to give, in order to preserve a powerful social position through the signalling and demonstration of wealth, fortune, being blessed by the gods or spirits, etc. This obligation goes hand in hand with the compulsory invitation of others, i.e. the spread of information to all potential receivers of a gift-giving occasion, for instance the invitation to a feast. Second, the invited are obliged to accept the invitation and are also obliged to accept a gift. A gift cannot be refused. Instead, as Mauss writes, a burden is attached to it and the receiver of the gift has to carry this burden. Third, the burden is expressed by the obligation to reciprocate the gift in the future. Indeed, by fulfilling of the latter obligation a new round of reciprocal exchange is likely to start.

Violations of one of these obligations, e.g. not to invite, to decline an invitation, to reject a gift, or an insufficient reciprocation of the gift, inevitably leads to social consequences for the offender or her group. Examples are loss of social esteem, status, power, etc. As Mauss (1990) shows, these patterns of exchange are universal even if the radical form of it - the potlatch - constitutes an exception. However, it is plausible to assume that elements of this form of gift exchange exist in contemporary 
societies, for instance in customer-firm relations. As a consequence thereof, one can ask whether the concept provides guidance for the successful implementation of a participative pricing mechanism.

Before addressing this question in the next section, I will discuss the trust game (TG) briefly. The TG is a workhorse in behavioural economics and illustrates not only the existence of other regarding preferences, but also the way how reciprocity can be measured. It has been used to model PWYW pricing as a game tree (Greiff and Egbert 2016b). The TG can also be used to illustrate the main difference between the Gift and reciprocity considerations in behavioural economics.

The TG is a sequential game with two players. Both players receive an endowment and the first player, the sender, can pass any share of her endowment to the second player, the receiver. Both players know that this share is exogenously multiplied, for instance tripled by the experimenter before it is passed to the receiver. Next, the receiver can return any amount to the sender. The multiplication allows the receiver to reciprocate the sender. However, she may also return nothing. The sender is considered to be a 'trustor' who is confident that the receiver - a 'trustee' - reciprocates trust. After Berg, Dickhaut and McCabe (1995) had introduced the experiment, it was tested in many different settings (for a survey see Ortmann, Fitzgerald and Boeing 2000; for a meta-analysis see Johnson and Mislin 2008). Results are by and large robust, even if regional differences are documented.

The typical interpretation of the TG is that the trustor's decision is a signal of trust and the trustee's decision (reciprocation) is a signal of trustworthiness. Based on this assumption, results about trustees' behaviour can be formulated. About half of the trustees betray the trustors' trustworthiness and return (almost) nothing, while the other half of the trustees honour trust by returning more than the received amount. The decision to honour trust can be motivated by positive reciprocity, i.e., a propensity to reward friendly behaviour. The TG resembles to a considerable degree a PWYW pricing situation where a seller offers a product to a buyer and the latter can reciprocate the offer by a payment (Greiff and Egbert 2016b).

If the TG is compared with the Gift context, three main differences are apparent. Firstly, in the TG players are mostly anonymous, i.e. they have no identities. Individual preferences with respect to identity are absent. Secondly, the trustee in the TG has no exogenously set obligation to reciprocate the sender. Norms of reciprocity may be present, but are not dictated by society. Thirdly, TGs are often one shot games and do not simulate repeated interaction. The Gift however implies long-term repeated interaction. All three aspects, 'identity', 'obligation', and 'repeated interaction' are crucial in the Gift context and are likely to enforce reciprocal behaviour. What we can learn from the results of TG is 
that even without the three harsh institutional constraints a number of receivers behave reciprocally.

\section{The Gift and the Buyer: PWYW pricing}

This section addresses the questions how the concept of the Gift provides guidance for a successful application of a PWYW pricing mechanism. Under PWYW pricing a seller is comparable to a gift-giver or a trustor, and buyers are trustees who have the option to reciprocate. Next, four interrelated aspects, which can be considered as necessary preconditions for the application of PWYW pricing, are identified for such a seller-buyer relation.

Kim, Natter and Spann (2009) popularized PWYW pricing as a topic of scientific research. They emphasize the importance of personal interaction between a seller and a buyer. The PWYW contexts that they investigate are not anonymous, for instance PWYW pricing in a restaurant. Identity between the two parties is created through face-toface interaction (see also Hilbert and Suessmair 2015). Indeed, this is very similar to the Gift as illustrated for potlatches. Identity of gift-givers and gift-receivers is a crucial factor in order to make this exchange system work (see the literature mentioned by Kim, Natter and Spann 2009: 46; see additionally Regner and Riener 2012). Non-anonymity through social interaction of the involved parties in a PWYW interaction can be considered the first aspect.

Closely related to non-anonymous exchange is the visibility of the exchanged items and related payments. Information about the size and the value of the exchanged items can be made public, exactly like in a potlatch. It is in the interest of the giver to make the value of her gift public. The visibility of the exchanged items (for givers, receivers but also for bystanders) is an integral part of the institutional setting of a potlatch. The visibility of exchanged items enables, on the one hand, information sharing of people's activities, and, on the other hand, the implementation of social norms. In a business context, it is in the interest of a seller to make the quality of her products known to potential buyers. Additionally, under PWYW pricing it is also in the seller's interest to get to know individual payments of buyers. Furthermore, it may also be in the interest of the buyer to inform the seller or other buyers about her payment. In particular, if buyers have status and self-image concerns, a PWYW mechanism should be constructed in such a way that payments become visible. Visibility of buyers' payments for the seller and other buyers is the second aspect.

This goes hand in hand with another feature pertinent to the Gift. In order to have effects from the visibility of gift-giving the exchange partners must have a similar value system. This value system may refer (i) to the goods being exchanged, (ii) to the pricing mechanism itself, or 
(iii) to social norms of exchange. In economic terms, buyers and sellers should have similar preferences viz. value systems. If the value system is related to the product being sold (e.g., sport products, music songs of a specific band), sellers and buyers may follow norms prevalent within the sports community or within the fan community of the music band. Results of TG hint that if information about players is introduced, a positive effect on reciprocal behaviour may occur (e.g., Fershtman and Gneezy 2001).

Information about individuals in a PWYW pricing context can be considered as signals that specific value systems are in place. Santana and Morwitz (2015) address a similar aspect in PWYW experiments and field studies. They measure social value orientation with respect to exogenously implemented norms and find that norms have effects on the amount being paid. Gravert (2017) addresses similar structures. She tests PWYW pricing for books sold at a charitable bookstore and finds that buyers pay more for the books when they are reminded of having a membership card of the bookstore (see also results from Regner 2015). Mauss elaborates on the concept of the Gift by referring to ethnographic and historic examples. All groups and societies analyzed by Mauss follow a group-specific internal value system. That is why the third aspect relevant for implementing PWYW pricing can be summarized as a 'shared value system' of sellers and buyers.

Finally, the Gift is related to repeated interactions. Repeated interaction allows the long-term enforcement of social norms. This is also the case if a seller-buyer relation is not one shot but resembles repeated exchange with the same individuals. In such a repeated interaction, on the one hand the seller can lose her reputation if the goods she offers are of low quality which a buyer can detect after purchase. The latter can negatively reciprocate the low quality in future purchases or abstain from buying. On the other hand, a buyer who does not contribute adequately to the costs of production in a PWYW setting is at risk of receiving no products or products of low quality in the future. Thus, a situation of repeated interaction with the same players is likely to increase the quality of the products offered as well as the prices being paid (e.g., Mak et al. 2015). PWYW pricing is, hence, applicable for repeated interaction with the same buyers. This can be considered the fourth aspect.

The above four aspects seem to be essential preconditions if PWYW pricing is not a short-term but a long-term pricing strategy for a seller, respectively a company. They can be directly derived from the Gift. As one can see, they are largely overlapping and not independent from each other.

\section{Conclusion}

This paper addresses the recently popular specific participative pricing mechanism of Pay-What-You-Want pricing for a company. An intriguing 
question is how the mechanism can be applied in business contexts. In case studies, field experiments and laboratory experiments the influence of different variables and settings on payments have been tested. In contrast to these empirical studies this paper has addressed the same question by referring to Marcel Mauss's concept of the Gift. Mauss has argued that individuals are individually and socially motivated and his masterpiece, the Gift, shows similarities to topics discussed in behavioural economics, for instance reciprocal behaviour. Nonetheless, the Gift has not been used to examine PWYW pricing so far.

The application of the Gift to PWYW pricing shows that four preconditions appear to be necessary in order to make PWYW pricing a successful long-term pricing strategy that generates profits for a seller. These have been identified in this paper. They are (1) non-anonymity of the involved persons, (2) visibility of buyers' payments to the seller, (3) mutual value system, and (4) repeated interaction among the individuals.

The analysis does not deny that other factors, which have been intensively discussed and empirically tested in the PWYW literature, are less prominent. On the contrary, they are immensely significant, for instance reference prices of a product, market structure, type of goods being offered, etc. However, only very few applications of PWYW pricing as a long-term pricing strategy have been documented so far. The paper has provided some insights into the concept of the Gift as guidance to applications which resemble systems of repeated reciprocity. This paper has sought to apply the well known concept to a specific mechanism in a modern business context.

\section{References}

Albert, M., Güth, W., Kirchler, E., and B. Maciejovsky. 2007 'Are we nice(r) to nice(r) people? An experimental analysis.' Experimental Economics 10: 53-69. https://doi.org/10.1007/s10683-006-9131-3

Berg, J., Dickhaut, J., and K. McCabe. 1995 'Trust, reciprocity, and social history.' Games and Economic Behavior 10(1): 122-142. https://doi.org/10.1006/game.1995.1027

Bowles, S., and H. Gintis. 2004 'The evolution of strong reciprocity: cooperation in heterogeneous populations.' Theoretical Population Biology 65: 17-28. https://doi.org/10.1016/j.tpb.2003.07.001

Bowles, S., Choi, J-K., and A. Hopfensitz. 2003 'The co-evolution of individual behaviors and social institutions.' Journal of Theoretical Biology 223: 135-147. https://doi.org/10.1016/s0022-5193(03)00060-2

Carrier, J. G. 2014 'Economic deviance.' Anthropology Today 30(6): 1-2. https://doi.org/10.1111/1467-8322.12139 
Douglas, M. 1990 'Introduction.' In M. Mauss The Gift: The Form and Reason for Exchange in Archaic Societies (translated by W. D. Halls), pp. 17. London: Routledge.

Egbert, H. 2015 'The return of Homo oeconomicus to anthropology: comment on economic deviance.' Anthropology Today 31(3): 17. https://doi.org/10.1111/1467-8322.12176

Egbert, H. 2017 'The Gift and the Centipede.' (mimeo).

Falk, A. 2007 'Gift exchange in the field.' Econometrica 75(5), 1501-1511. https://doi.org/10.1111/j.1468-0262.2007.00800.x

Falk, A., and U. Fischbacher. 2006 'A theory of reciprocity.' Games and Economic Behavior 54: 293-315.

https://doi.org/10.1016/j.geb.2005.03.001

Fehr, E., and U. Fischbacher. 2003 'The nature of human altruism.' Nature 425: 785-791. https://doi.org/10.1038/nature02043

Fehr, E., and S. Gächter. 1998 'Reciprocity and economics: the economic implications of Homo Reciprocans.' European Economic Review 42: 845859. https://doi.org/10.1016/s0014-2921(97)00131-1

Fehr, E., and S. Gächter. 2000 'Fairness and retaliation: the economics of reciprocity.' Journal of Economic Perspectives 14(3): 159-181.

https://doi.org/10.1257/jep.14.3.159

Fehr, E., and K. M. Schmidt. 2006 'The economics of fairness, reciprocity and altruism: experimental evidence and new theories.' In S-C. Kolm and J. Mercier Ythier (eds.) Handbook of the Economics of Giving, Altruism and Reciprocity, pp. 616-690. Amsterdam: Elsevier. https://doi.org/10.1016/s1574-0714(06)01008-6

Fehr, E., Kirchsteiger, G., and A. Riedl. 1993 'Does fairness prevent making clearing? An experimental investigation.' Quarterly Journal of Economics 108(2): 437-460. https://doi.org/10.2307/2118338

Fehr, E., Kirchsteiger, G., and A. Riedl. 1998 'Gift exchange and reciprocity in competitive experimental markets.' European Economic Review 42: 134. https://doi.org/10.1016/s0014-2921(96)00051-7

Fershtman, C., and U. Gneezy. 2001 'Discrimination in a segmented society: an experimental approach.' Quarterly Journal of Economics 116(1): 351-377. https://doi.org/10.1162/003355301556338

Gerpott, T. 2017 'Pay-What-You-Want pricing: An integrative review of the empirical literature.' Management Science Letters 7: 35-62. https://doi.org/10.5267/j.msl.2016.11.004

Gravert, C. 2017 'Pride and patronage - pay-what-you-want pricing at a charitable bookstore.' Journal of Behavioral and Experimental Economics (forthcoming). https://doi.org/10.1016/j.socec.2017.01.009 
Greiff, M., and H. Egbert. 2016a 'A survey of the empirical evidence on PWYW pricing.' Bulgarian Economic Papers (BEP 02-2016). Sofia: Sofia University.

Greiff, M., and H. Egbert 2016b 'The pay-what-you-want game and laboratory experiments.' MPRA Paper No 75222 (November 2016).

Hann, C. 2006 'The gift and reciprocity: perspectives from economic anthropology.' In S-C. Kolm and J. Mercier Ythier (eds.) Handbook of the Economics of Giving, Altruism and Reciprocity, chapter 4. Amsterdam: Elsevier. https://doi.org/10.1016/s1574-0714(06)01004-9

Hart, K. 2007 'Marcel Mauss: in pursuit of the whole.' Comparative Studies in Society and History 49(2): 473-485. https://doi.org/10.1017/s0010417507000564

Hilbert, L. P., and A. Suessmair. 2015 'The effects of social interaction and social norm compliance in pay-what-you-want situations.' American Journal of Industrial and Business Management 5: 548-556. https://doi.org/10.4236/ajibm.2015.58054

Johnson, N., and A. Mislin. 2008. 'Trust games: a meta-analysis.' Journal of Economic Psychology 32: 865-889. https://doi.org/10.1016/j.joep.2011.05.007

Kim, J-Y., Natter, M., and M. Spann. 2009. 'Pay What You Want: a new participative pricing mechanism.' Journal of Marketing 73(1): 44-58. https://doi.org/10.1509/jmkg.73.1.44

Krzyżanowska, M., and J. Tkaczyk. 2016 'Pay-what-you-want as a participative pricing mechanism: meta-analysis of development and knowledge dissemination.' International Journal of Management Cases 18(2): 21-38.

Léon, F. J., Noguera, J. A., and J. Tena-Sánchez 2012 'How much would you like to pay? Trust, reciprocity and prosocial motivations in El trato.' Social Science Information 51(3): 389-417. https://doi.org/10.1177/0539018412441756

Liebersohn, H. 2011 The Return of the Gift. Cambridge: Cambridge University Press.

Mak, V., Zwick, R., Rao, A., and J. A. Pattaratanakun 2015. “Pay what you want' as threshold public good provision.' Organizational Behavior and Human Decision Processes 127: 30-43. https://doi.org/10.1016/j.obhdp.2014.11.004

Malinowski, B. 1922 Argonauts of the Western Pacific. New York: E.P. Dutton.

Malinowski, B. 1926 Crime and Custom in Savage Society. London: Kegan Paul, Trench, Trubner \& CO. LTD.

Mauss M. (1923/1924) ‘Essai sur le don. Forme et raison de l'échange 
dans les sociétés primitives.' L'Année Sociologique 1923/24(1): 30-186. https://doi.org/10.1522/cla.mam.ess3

Mauss, M. 1990 The Gift: The Form and Reason for Exchange in Archaic Societies (translated by W. D. Halls). London: Routledge.

Mercier Ythier, J. 2006 'The economic theory of gift-giving: perfect substitutability of transfers and redistribution of wealth.' In S.-C. Kolm and J. Mercier Ythier (eds.) Handbook of the Economics of Giving, Altruism and Reciprocity, chapter 5. Amsterdam: Elsevier. https://doi.org/10.1016/s1574-0714(06)01005-0

Oosterbeek, H., Sloof, R., and G. van de Kuilen 2004 'Cultural differences in Ultimatum game experiments: evidence from a meta-analysis.'

Experimental Economics 7: 171-188. https://doi.org/10.1023/b:exec.0000026978.14316.74

Ortmann, A., Fitzgerald, J., and C. Boeing 2000 'Trust, reciprocity, and social history: a re-examination.' Experimental Economics 3(1): 81-100. https://doi.org/10.1007/bf01669208

Park, S., Nam, S., and J. Lee 2016 'Charitable giving, suggestion, and learning from others: pay-what-you-want experiments at a coffee shop.' Journal of Behavioral and Experimental Economics (forthcoming). https://doi.org/10.1016/j.socec.2016.04.010

Parry, J. 1986 'The gift, the Indian gift and the 'Indian Gift". Man 21(3): 453-473. https://doi.org/10.2307/2803096

Regner, T. 2015 'Why consumers pay voluntarily: evidence from online music.' Journal of Behavioral and Experimental Economics 57: 205-214. https://doi.org/10.1016/j.socec.2014.10.006

Regner, T., and G. Riener 2012 'Voluntary payments, privacy and social pressure on the internet: a natural field experiment.' DICE Discussion Paper, No. 82, Düsseldorf Institute for Competition Economics (DICE).

Reisman, R. 2016. FairPay: Adaptively Win-Win Customer Relationships. Business Expert Press.

Riener, G., and C. Traxler. 2012 'Norms, moods, and free lunch: longitudinal evidence on payments from a pay-what-you-want restaurant.' Journal of Socio-Economics 41(4): 476-483. https://doi.org/10.1016/j.socec.2011.07.003

Santana, S., and V. G. Morwitz. 2015. 'Because we're partners: how social values and relationship norms influence consumer payments in paywhat-you-want contexts.' Advances in Consumer Research 43, 8-9.

Weiner, A. 1992. Inalienable Possessions: The Paradox of Keeping-While Giving. Berkeley and Los Angeles: University of California Press. 
Henrik Egbert works on topics in economic anthropology, in particular illegal trade, entrepreneurship and markets. He received formal training in microeconomics, institutional and behavioral economics. After obtaining a PhD from Bayreuth University and doing his habilitation at Giessen University, he has been professor of economics at Anhalt University of Applied Sciences, Germany. 